\title{
Echo Chambers and Online Radicalism: Assessing the Internet's Complicity in Violent Extremism
}

\author{
Kieron O'Hara \\ Web and Internet Science Group \\ Electronics and Computer Science \\ University of Southampton \\ Highfield \\ Southampton SO17 1BJ \\ United Kingdom \\ kmo@ecs.soton.ac.uk
}

\section{David Stevens}

\author{
School of Politics \\ University of Nottingham \\ University Park \\ Nottingham NG7 2RD \\ United Kingdom
}

David.Stevens@nottingham.ac.uk

\begin{abstract}
The authors consider claims made by various authors that the use of filtering and recommendation technology on the Internet can deprive certain communities of feedback, and instead amplify groups' viewpoints, leading to polarization of opinion across communities, and increases in extremism. The 'echo chamber' arguments of Cass Sunstein are taken as representative of this point of view, and examined in detail in the context of a range of research, theoretical and empirical, quantitative and qualitative, in political science and the sociology of religion, from the last quarter century. The authors conclude that the case has not been made either (a) that echo chambers are necessarily harmful, or (b) that the Internet is complicit in their formation.
\end{abstract}

\section{Introduction}

The Internet is celebrated for disseminating knowledge and supporting conversation, dialogue and debate. Its decentralization allows anyone to post opinions online or link to other papers. The gatekeeping characteristic of the mass media has not been eradicated - search engines are important, but their presentation of content is at least partially based on the democratic notion of emergent link structures.

Yet this happy characterisation has been challenged by the counter-argument that the Internet and the Web are also tools for excising dissenting voices from individuals' purview, which will tend to magnify and reinforce their prejudices. As an example of the spread of that meme, a balanced discussion of this issue in Wired recently was headlined: "The internet glosses over life's ambiguities with false certainty, and we do little to search out these important grey areas" (Martin 2013). The worry is that this "echo chamber" effect will coarsen online debate.

Filtering and recommendation have been fingered as responsible technologies: people restrict the feedback they receive, distorting their psychosocial lives. Pariser has argued that recommendation and filtering software creates a 'filter bubble', "a unique universe of information for each of us" (Pariser 2011). In contrast, old-style edited newspapers aggregate material deemed essential and topical by an editorial team, and present it to the reader as 'the state of the world'. It is obviously incomplete and biased, but there is no reason to think that it won't diverge from, and therefore challenge, the reader's biases and knowledge (Mutz \& Martin 2001).

Furthermore, messages are crucially simplified in order to facilitate communication and transmission. Sim has argued that such simple messages, and the certainty with which they are held, are increasingly prevalent in the modern world (Sim 2004), while Mandaville has asserted in one specific case with major political consequences that 
new media are creating a 'soundbite Islam' (Mandaville 2002, 70) which militates against the informed interaction with embedding societies that commentators such as Harris argue is the root of religious moderation, and a brake against radicalism (Harris 2005).

Echo chambers have wider social implications. For Lanier, only the Web as it is currently constituted could have produced such behaviour, by its support of "anonymous, fragmented communication." "New patterns of social connection that are unique [our emphasis] to online culture have played a role in the spread of modern networked terrorism ... jihadi chat looks just like poodle chat" (Lanier 2011, 62). Barker has argued in the context of radical and uncompromising online religions that, "as such a polarized worldview could be endangered by qualifications or questioning, any middle-way option or ambiguity is likely to be demonized as part of the bad, the false and/or the satanic alternative" (Barker 2005, 69).

These wider implications play out into policy - if echo chambers are important in fomenting extremism, then policymakers will be compelled to act. "It is important ... to create alternative media that brings together left, right and center" (An et al 2013). If we define 'radicalism' as a belief/behaviour nexus in considerable tension with the embedding society, and 'extremism' as the violent pursuit of radical goals, radicalism per se is not a legitimate target of official policy, but extremism is (Stevens \& O'Hara 2014).

Our aim in this paper is to examine critically the argument that 'echo chambers' are socially harmful and are propagated to an unusual and undesirable degree by Internet technology. We will focus on a particular argument of Cass Sunstein (2007), which is representative, well-developed and well-defended. We will review evidence from political and sociological analysis, qualitative and quantitative, theoretical and empirical, going back two decades.

The focus on policy and ideological outcomes means that this is more than a big data/network analysis problem. The question is not whether there are echo chambers on the Internet (which may be discoverable by network analysis tracing connections between interlocutors over time). The two key questions here are whether the Internet is complicit in the growth of echo chambers, and if that is so, whether it is necessarily a bad thing (and therefore whether it should be the target of a policy focus). Big data is of course an important ingredient in these discussions, but it is silent about the offline comparator, and hardly decisive in questions of value.

Our paper has five further sections. First we outline Sunstein's argument. The next two sections review research from sociology, politics and network science to evaluate the case for policy responses to echo chambers, measuring echo chambers against the ideal characteristics of public discussion forums and collaborative spaces, and considering empirical work on the evolution of individuals' networks in the digital age. The penultimate section considers assumptions about the spread of ideas through networks that underpin the echo chamber argument, before rounding off with a conclusion. Our previous work in this area has focused on religious extremism (O'Hara \& Stevens 2009, Stevens \& O'Hara 2014), but the arguments here are meant to apply more widely to political or nihilistic extremism generally. Except for an extended example on Islamism, the arguments are not specific to religion. 


\section{Sunstein on echo chambers}

Sunstein argues that a well-functioning system of free expression must expose people to materials they would not have chosen in advance, and in a democratic polity most citizens must have a range of common experiences to support their mutual understanding and sympathy (2007, 5-6). If these two requirements are not fulfilled there will be three major unfortunate unintended consequences. First, there will be social fragmentation, as diverse groups polarise. Second, people will use available technology to create information goods tailored to themselves, rather than creating goods that are valuable for many people. Third, satisfaction of preferences will be taken as definitive of people's well-being, ruling out alternative conceptions that take into account the possibility of extra value being provided by heterogeneous influences (2007, 44-45).

US Citizens have a constitutional right of access to public forums, where they can address other citizens publicly and freely (Sunstein 2007, 22-29). This implies four things. (1) Those with a point of view or a grievance can publicise it. (2) They can tailor their arguments to make them more effective in different contexts. Those who wish to complain to legislators can demonstrate outside Parliament, while those who wish to complain about a corporation's attitude towards climate change can peacefully picket their head offices. (3) Other citizens will thereby be exposed to arguments or points of view they would not have chosen. (4) As public spaces, some will be subsidised by the government in its role as guarantor of free speech, but Sunstein also argues that the private mass media act as public forums in this sense.

Such forums are extremely important for supporting deliberative democracy, in contrast with the direct democracy ideas of gauging, aggregating and counting votes or opinions on specific issues without mediation. In a direct democracy there is no particular need to avoid partisanship or promote compromise, as long as there is an agreed decision mechanism; though perhaps desirable, dialogue is inessential. Sunstein also contrasts political and consumer sovereignty $(2007,38)$. The former, unlike the latter, goes beyond the satisfaction, where possible, of the consumer's immediate preferences, to matters such as accountability, liberty and reasoned debate.

In contrast to the mass media, argues Sunstein, the Internet is not a public forum which can support political sovereignty in deliberative democracies (2007, 54-55), because of the technology's support for users' tendencies to use personalization to read and link to like-minded resources, a tendency that has been shown, e.g., with respect to political blogs and many other areas (Adamic \& Glance 2005, Hargittai et al 2008, Lucioni 2013). Hate groups are even less tolerant and cosmopolitan; conspiracy theories are sheltered from objective criticism, while evidence is presented selectively (Kay 2011, 227-259, Sunstein 2006, 191).

Sunstein is especially concerned with group polarization, where members tend to become less diverse over time, and the group more coherent (2007, 60-64). This will promote extreme positions, for three reasons. First, members are disproportionately exposed to persuasive arguments from one side only. Second, they adopt positions to appear in a favourable light to their peers. Third, increased solidarity leads to greater confidence, which in turn is associated with more extreme positions. Hence, "from the evidence thus far, it seems plain that the Internet is serving, for many, as a breeding ground for extremism, precisely because like-minded people are deliberating with greater ease and frequency with one another, and often without hearing contrary views" $(2007,67)$. 


\section{Echo chambers and public forums}

Sunstein's argument depends for its force on triangulating between the Internet and an ideal of public debate and collaboration. In this section, we consider this assumption, measuring his evidence against the ideas of Jürgen Habermas, perhaps the most influential theorist of rationality and public communication. The Internet is not uniform in its promotion of effective debate, and the arguments are at best not clear cut.

\section{The Internet as a public forum}

Habermas' 'ideal speech situations,' standards for a communicative discourse that can facilitate self-correcting social learning, are characterised by four important properties: (i) no one capable of making a relevant contribution has been excluded, (ii) participants have equal voice, (iii) they are internally free to speak their honest opinion without deception or self-deception, and (iv) there are no sources of coercion built into the process and procedures of discourse (Habermas 1989, 2008). Sunstein explicitly rejects the claim that the blogosphere is "a vast public meeting of the kind that Jurgen Habermas describes" on the ground that group polarisation makes that impossible. "The challenge to the Habermasian understanding [of the blogosphere] is that because of self-sorting, people are often reading like-minded points of view, in a way that can breed greater confidence, more uniformity within groups and more extremism" (Sunstein 2008, 87).

How should we judge the blogosphere using Habermasian concepts? Characteristics (i)-(iv) surely apply to it in some degree. (i), (iii) and (iv) seem relatively uncontroversial, but Hindman has argued contra (ii), following a survey of popular political bloggers, that participants in the blogosphere, as in other offline media, do not have equal voice. "Overwhelmingly, they are well-educated white male professionals. Nearly all the bloggers in our census were either educational elites, business elites, technical elites, or traditional journalists" (Hindman 2009, 128). The scale-free link structure of the Web tends to produce a Matthew effect where success reinforces success. A page with many inbound links is more likely to be discovered by someone searching for political or religious information, and will therefore become even more likely to be linked to. To that extent, voices in the blogosphere are not equal.

Finding more evidence of bias in the blogosphere and other social media is a nontrivial exercise, partly because it is hard to quantify what is on there, and partly because technology inevitably filters what people will see (Lin et al 2011). Searches for bias at scale need to be automated, and the techniques for doing this are not currently sophisticated (on the other hand, manual bias detection is often in the eye of the beholder, and hard to make objective). Bias detection itself tends to be biased toward the main fault lines in the US context (conservative/liberal), which may not be representative of partisan issues in the rest of the world. Furthermore, the issue is further complicated by the close links between the online provision of news by the major offline providers (An et al 2012), so bias in one sector will feed back into the other. It is also worth noting that identifying partisan consumers of online news is hard as they do not appear to differ demographically from their less biased brethren (An et al 2013).

However that may be, the bias of the blogosphere does not seem to be objectively worse or more corrosive than that of the traditional media. (Lin et al 2011) found that 
blogs are not less biased than the news, but are biased in different ways. Their support of particular parties and candidates is weaker than the mass media, but they are more susceptible to the preferences of their network and exogenous events (such as elections). People tend to share content from partisan sources (An et al 2013), but sharing is a committed and other-directed act which in any walk of life is surely much more to do with the promotion of one's own views than other types of political reflection that a person might indulge in. It would be very unusual and counterproductive for a person to be unbiased in the very act of persuasion.

Nevertheless, neither censorship nor editing is a feature of the Web, and so the Habermasian conditions still arguably apply. For instance, Gary Bunt's detailed treatment of Islam online seems consistent with the ideal. "Blogs have become a significant adjunct to, if not the primary thrust of, conversation, intellectual stimulus, and Muslim networking. They reach down into the Long Tail of segmentation and nuanced content delivery, with highly specialized content emerging throughout sectors of the Islamic blogosphere" (Bunt 2009, 133). Although Habermas has retreated from early hopes that ideal speech situations would guarantee ethical discourse, it might still be argued that blogging is an important area which could in the aggregate approach the ideal of disinterested pursuit of truth (however partisan the individual blogs), and that a debate in the blogosphere would be an important standard for ideal speech situations.

Whether or not this is Habermas' view, the blogosphere meets many if not all demands for an ethical forum for debate and discourse. Yet Sunstein rejects the idea that unconstrained online discussion counts against the echo chamber thesis, and argues that the Internet is complicit in the degradation of the public sphere, concluding that "blunders, confusion, and extremism are highly likely, not in spite of the blogosphere but because of it" (Sunstein 2007, 150).

\section{Reiteration of founding beliefs}

One can admit the echo chamber effect without taking on the whole of Sunstein's pessimistic thesis. Beliefs aren't simply propositions to which we assent, or store in our minds, like the contents of a filing cabinet. They underpin action, sometimes are crafted post hoc to rationalise it, sometimes postulated to explain it. Sometimes they co-exist precariously with doubt. Sometimes they promote solidarity. They exist in a psychological and social context, in which an echo chamber may have a role to play. In that event, it may be liberating, allowing the development of a more authentic, less coercively-determined, character.

In the Habermasian public sphere, the emphasis is on discourse, rationality and universality, but sometimes a group may need to bond and emphasise its solidarity. Discussing politics with those with whom one agrees helps mitigate issues of conflict that hinder action (Mutz 2002), and political participation is fostered by discussions of politics with small numbers of like-minded individuals (Kwak et al 2005). As noted earlier, those who share news content tend to share partisan sources (An et al 2013). David Weinberger, Howard Dean's Senior Internet Advisor in his Presidential run in 2004, for instance, argued that although Dean's eye-catching but ill-fated Internet campaign looked like an echo chamber, this was not a failing of the campaign (Weinberger 2004). Not all political discourse needs to be of the Habermasian type.

(Gruzd \& Roy 2014) found evidence that clusters of ideological partisans on Twitter in Canada during the 2011 Federal Election would engage with ideological opponents, 
but that these interchanges rarely changed minds. This not only chimes in with the discovery that social media bias is related to exogenous events (An et al 2013), but also undermines the idea that simply exposing people to alternative points of view would undo echo chambers. Political positioning is an important aspect of identity, and - certainly at election time - partisans are up for debate. Sometimes political action is focused on bolstering one's own forces. Failure to persuade others does not mean that one is persuaded by their arguments instead.

How might this thought play itself out with radical or extreme philosophies? Let us consider the idea of the umma, or global Muslim community, which has become the focus of some Islamist political actions, including but not restricted to violent terrorism (Scruton 2002, Roy 2004). It has been suggested that the Internet is allowing the umma to be reimagined, creating a virtual community (Mandaville 2001) facilitated by the compression of space and time by information and communication technologies (Giddens 1980, 90-108, Castells 2000, 460-499). Despite the manifest diversity of Islamic voices online, the existence of international communication networks that connect Muslims from diverse communities and allow virtually instantaneous communication might be expected to foster pan-national solidarity.

However, that very plurality undermines the idea that everyone will speak with the same voice. El-Nawawy and Khamis argue that in Islamic debate the Internet reproduces arguments about authority in new contexts, rather than supporting a new authoritative consensus (2009, 113-116). The whole idea of an authoritative Islamic source, already a highly qualified notion, comes under threat because plurality of opinion about doctrine in the Islamic world transmutes online into plurality of opinion about who is authoritative about doctrine, and which websites provide the best discussion.

The creation of a space where people can discuss or argue is a more important effect than echo chambers; the purposes of communicants are met very well by such spaces even if they have the characteristics of echo chambers. For example, for immigrant groups religion has an important role in the construction of a new life in unfamiliar and sometimes hostile surroundings (el-Nawawy \& Khamis 2009, 119-120), so the argument of (Campbell \& Kwak 2011) that large networks of like-minded people connected via mobile technology can encourage political participation suggests that networks based around religion could promote constructive engagement. This is surely a precondition of any kind of fruitful interaction between the embedding community and the immigrants, even if it simultaneously creates the potential for conflict.

\section{Disagreement and civility}

The partisan links between blogs have been proffered as evidence for the echo chamber thesis, but the picture is muddier. In a study of patterns of linking, Hargittai and colleagues discovered the separation between liberal and conservative blogs to which other commentators had drawn attention, but also found that blogroll links take up a large proportion of the total number of links, and are overwhelmingly to sites of a similar political creed. Because it is a fixed item, the blogroll has the artificial effect of lowering the proportion of ideological opponents linked to (Hargittai et al 2008, 76-77).

Although most of the other links that appear in posts connect with ideological friends, there is a minority of in-post links connecting to opponents (in their sample, $12 \%$ of 
outbound links from conservative sites and $16 \%$ of outbound links from liberal sites). Only a very small number of sites never linked to opponents. They also found that, contrary to the thrust of the echo chamber thesis, there was no evidence that polarisation was (still) occurring - although the data were not very comparable over time, as far as could be seen the number of cross-ideological links was not decreasing (Hargittai et al 2008, 78-80). Discussion is more polarised close to elections, but it has also been found that voters in the US are more politically interested and aware in Presidential election years (Mossberger et al 2008, 67-93), so this is not necessarily a bad thing.

When in-post cross-ideological links are examined in more detail, there is evidence of interaction and conversation. Hargittai et al classified the links by their argumentative purpose, and were able to show that bloggers had a range of reasons for citing their opponents, even when they were being admittedly and explicitly negative (2008, 8184). There is nothing in this analysis that specifically undermines the Sunstein thesis, but his empirical work is relatively abstract. The detail of the interactions across the American ideological divide connotes a measure of civility and dialogue that suggests that group polarisation is not necessarily a disaster for political discourse.

This is backed up by other evidence. For instance, a study about the 2010 US midterms showed that $55 \%$ of voters believed that the Internet increased the impact of extreme views (against 30\% who thought it reduced it), but actually only 34\% of voters who used the Internet as a source of news websites admitted to seeking out websites that shared their point of view (Smith 2011).

The arguments that deny that echo chambers can be public forums are finely balanced. However, we should acknowledge that, although echo chambers can diminish authenticity by constraining the influences on people, in different circumstances, they can also support it by allowing people to experiment with socially innovative identities. Furthermore, disagreement need not preclude civility.

\section{The Internet as a collaborative space}

Sunstein (2006) is less sanguine about the ability of the Internet to bring people together constructively than many other accounts of Web-enabled mass collaboration (Surowiecki 2004, Tapscott \& Williams 2007, 2010). For instance, Leadbeater directly contradicts Sunstein's thesis when he asserts that "the best way to find out which blogs are good is to rely on the judgements of other web users whom you trust" (Leadbeater 2008, 33).

All would agree that ideal collaboration (a) avoids groupthink, (b) internalises critical analysis within the group, and (c) brings local perspectives and a range of interests into play. For Sunstein, this requires that one is exposed as well to the judgments of those whom one doesn't trust. Conversely, he argues that opinion is likely to be rendered more extreme if one relies solely on those one trusts. Furthermore, anyone wishing to debate or establish or spread his opinions is perfectly capable of isolating himself from alternate views because he has been technologically enabled so to do.

Much depends on the perspective one takes on Web phenomena, which are often emergent from micro-scale events, actions or agents (O'Hara et al 2013). For instance, Wikipedia qua encyclopaedia is an impressive and counterintuitive crowdsourced achievement. On the other hand, any individual article in Wikipedia will of necessity be written by a smaller number of people than the total of Wikipedians, and so one may be unwittingly and occasionally exposed to a biased account on controversial 
topics, or in arcane areas where the number of interested commentators is small and where the article might have been written by a tiny number of people.

Similarly, do we take the blogosphere as a single human construct where every opinion is monitored and countered by others, or do we focus on individual blogs or tightly linked groups which may be subject to strong bias only countered elsewhere? A neophyte coming fresh to such a group may well come to believe that, with its strong internal links, it is sufficiently diverse to subject strong claims to relevant scrutiny, but the appearance of debate and diversity could be misleading.

There is no correct answer here, but clearly Sunstein takes the second view. This is a finely-balanced and subtle issue, and the nature of a collaborating group will depend not only on its diversity. For instance, Leadbeater writes about the importance of a creative core of workers or thinkers in a crowdsourcing application $(2008,68)$, which to an extent can define and drive the mission of the group. The connection between the core and the mission exemplifies the dilemma: if the core is sufficiently welldefined to drive a successful crowd-based collaboration, it may also have enough power in the relevant community to ensure that only like-minded people participate.

Yet diversity isn't everything; expert networks can also produce echo chambers. Taleb has complained, particularly with respect to the world of finance, that expertise results in groupthink, restriction of possible outcomes or solutions considered, unimaginative prognoses for the future, focus on quantifiable risk at the expense of the unknown, unwillingness to think beyond accepted expert models of reality and a tendency to mistake the models for reality itself (Taleb 2007). Douglas Carswell MP turns the echo chamber argument around by arguing for the liberating powers of the Internet in comparison with the "tyranny" of a "self-referential" elite "who like to interpret the world for us, ... full of their own prejudices and presumption" (Carswell 2012, 159).

Of course, feedback is key to the emergence of useful macro-level properties. As long as decisions feeds back into the wider system, a parameter - the price, the ranking of a webpage, new links - is determined which will in turn affect further decisions (O'Hara et al 2013). Experts can insulate themselves from criticism through their social networks. As a community of users grows, planning for that community gets harder, while a system aggregating feedback from individual micro-level decisions is more likely to scale.

The Web enables wider scrutiny of decisions or ideas developed by small, inwardfacing groups of people. Congressman Todd Akin's views on rape and abortion were exposed as ill-informed and offensive when opened to discussion by a wider audience during the 2012 Missouri senate race (e.g. Kliff 2012). Introvigne argues that in sites devoted to marginal religious groups anti-cultists tend to be more active and more numerous than supporters; his evidence led him to conclude that "so far, this Internet arena has exhibited a better potential for destruction than for construction when it comes to marginal religious movements" (Introvigne 2005, 113). Indeed, the ideas of a group can even be challenged when only the group takes part. Piff and Warburg give the example of the Talisman discussion group devoted to examining the Baha' $i$ faith's theology, which could have been an echo chamber, but which in practice exposed ideological divisions in the Baha'i community and questioned mainstream Baha'i views; the site was eventually closed down by Baha'i elders (Piff \& Warburg 2005). Even if the Internet does create echo chambers, it also creates opportunities to evaluate their output, and the latter effect will in many cases outweigh the former. 


\section{The networked individual}

The echo chamber argument seems to suggest that technology is a homogeneous influence on an individual whose social context is, if not fixed, at least not particularly multidimensional. Yet this does not accord with experience. Wellman and colleagues have studied the network connections between individuals (mainly in North America), and argues that the evidence shows that the constraining scenario gives only a partial picture. People in a US survey reported that they had more offline friends on average in 2007 than they did in 2002, especially those who were heavy users of the Internet. Indeed, the real-world friendship networks of those heavy users not only grew quicker than any other group graded by level of Internet use, but by 2007 they were also on average larger in absolute terms than those of the other groups (Wang \& Wellman 2010). $35 \%$ of Canadian families feel technology has improved connections within their families, while only 5\% feel it has not (Wellman et al 2009). The division between our online and our offline lives is not so easy to draw (Wellman \& Haythornthwaite 2002, Wang \& Wellman 2010, Wellman 2012).

Wellman writes of networked individuals (Raimie \& Wellman 2012), who have partial membership of multiple networks, rather than permanent membership of settled groups. The growth of the Internet, and social networking in particular, has accelerated a trend for people to leave tight-knit groups, and to live in looser networks. People have moved from being group members to being individuals who gain much of the meaning and support in their lives from their networks. The result is a gain for most people at least of flexibility, choice and exposure to heterogeneous points of view. Social ties and events are now more likely to be focused around an individual, rather than a social unit such as a family, a neighbourhood or an organisation. Communications are person-to-person, rather than place-to-place, and people organise their own communications networks, rather than expecting heads of households, congregation pastors or work bosses to provide and monitor communication for them. These results parallel other findings that an apparent loss of social capital in modern societies are less to do with a solipsistic retreat by individuals, than with withdrawal into richer, more private social worlds of friends, family and work (Fischer 2005).

People now often have several networks, and the tight connections that we used to expect with individuals in a single network are replaced with looser and more opportunistic connections with many others in a diverse spread of networks. The idea of a single 'home' community or identity is far less applicable to many. This jumble of networks is harder for the individual to manage, but pays off via the spread of services and experiences one is able to receive (Raimie \& Wellman 2012). The picture is not always straightforward, and there are trade-offs between the diversity and complexity of one's networks and the amount of novel information or perspective that one can glean (Aral \& Van Alstyne 2011), but the evidence is still that technology enhances most people's social experience.

The epistemological situation which concerns Sunstein is less threatening in the Internet context than it was in more fixed societies. Because a community based on proximity, family and sameness of purpose facilitates very deep communication with a small number of members, it is hard for new ideas and knowledge to penetrate the group. On the other hand, if someone is interacting with multiple networks and communities, they, and their networks, are exposed to new ideas all the time. Each person who is a member of more than one network connects or bridges them. This 
may provide an explanation of the oft-noted point that traditional religions are in decline alongside the fixed-proximity networks upon which they thrived, and that those religions with a do-it-yourself aspect are flourishing in comparison (Roy 2004). Such religions provide more useful benefits for networked individuals, as well as supporting more flexible communication.

For our purposes, this seems to imply that even if some networks have echo chamber properties, and even if some individuals thrive on, or seek out, such networks, no-one would be trapped by the technology without hope of relief. This is not all-or-nothing: Putnam and Campbell found that for many Americans their social networks were centred on their church, and that, though "political messages can echo through any network of like-minded people, whether based on occupation, group membership, or some other characteristic, ... not all networks are equal. We suspect that when religion is the common thread that has woven a network together, the political information that circulates carries more moral weight - and is thus more persuasive" (Putnam \& Campbell 2010, 441) Yet this is still not necessarily a bad thing. People find it easier to join, rejoin and move between networks. Even if one network has an unhealthy effect on someone it does not follow that it is the only influence on the people within it. People move across and through a network of networks, and this widens the set of influences.

\section{Discussion: changing minds}

One interpretation of the goal of the radical group is to solve a public good problem. Certain aspects of their ideology can be seen as a public good (the good society), but society is organized so that individuals are incentivised to work against the provision of that good (hence the radical feels thwarted at every turn). When opposition to the good is seen by the group to be endemic, there is a greater tendency for the group's radicalism to morph into violent extremism. When the group sees no route from the current state to its goal, its investment in non-violence will not bring a return (Stevens \& O'Hara 2014).

The problem for the radical is how to work effectively for the goal (which is not a personal preference), and the problem for the radical group is how to organise to produce the goal, given that most people will work against it. From the radicals' point of view the mass of people is free riding on their efforts. The radicals, in contrast, place value directly on what they perceive as the collective benefit - and once sufficiently many people value these collective benefits highly (so that it becomes a social norm - what has been called a public-good transformation - Kerr 1992), conflicts of interest disappear. Thus radical groups flourish by producing other public goods, such as uncorrupt administration, education and health care (Berman \& Laitin 2008).

Radicals' networks play an important role in providing mechanisms to realise their goal. Most important is the existence of a clique or a central cluster, i.e. a subgroup of a wider group which is very interconnected, in that everyone in the subgroup knows most others in the subgroup. A network of radicals must have relatively poor communications links outside the clique, and reasonably good ones inside. The clique need not be particularly strongly interconnected, so members could be quite isolated inside it, but it should be able to cut off communications from heterodox sources, and provide good connections to orthodox adherents. 
It is easier to reach people with similar interests within cliques than across society. Hence spreading a particular message with modest resources is easier when addressing a clique. Because communication within a clique is relatively cheap, a radical can conserve resources, and use members' weak ties with other groups to communicate beyond. Marwell and Oliver (1993) have shown that the two pragmatic strategies of high reach and low selectivity (many people are contacted indiscriminately) and low reach and high selectivity (special efforts are made to contact those people who are receptive to the message) are both effective in getting agreement and action about a public good.

Online social networking may increase the influence of close connections with strong ties, leading to perpetual contact via mobile devices which could crowd out alternative sources of information. Gergen (2008) calls such close-knit networks monadic clusters, where individuals focus their attention on each other, gradually withdraw from wider society, and become over-sensitive to their own interests and concerns. This kind of monadic cluster is the sort of structure that would seem to be important.

Under such circumstances, it is hard to see religious or political extremists as being self-interested in traditionally-understood ways. The radical does not look as if he is trying to build up his social capital, for instance, or to implement a strategy of cost minimization - quite the opposite, in fact. If the echo chamber argument is correct, it would appear to be necessary to postulate homophily and identity as reasons to develop links to a network, and to explain the growth (or otherwise) of networks in terms of contagion from members to new members.

\section{Homophily}

The attraction felt by people of similar backgrounds is an important binding mechanism for groups. Most work on homophily has focused on similarities such as age, gender and race. But this mechanism does not support the Sunstein thesis that people can transcend attractors based on demography and physical proximity with an ideology, religion or a shared nihilistic disregard of embedding societies. Indeed, homophily based on proximity is a protection against ideologically-driven extremism, on the assumption that extremists are rare within geographical communities.

Some researchers have found strengthened ties based on religion (Schermerhorn 1977, Galaskiewicz 1979, McPhee \& Corman 1995), but online, solidarity is rarely produced by ideology alone. El-Nawawy and Khamis analyzed a small number of Islamic discussion forums, some characterized by very diverse networks, others by homogeneous ones (using language as a proxy for diversity). Arabic forums, whose members were relatively homogeneous culturally, ethnically and religiously, were more likely to evolve a pan-Arab or pan-Islamic consensus than English-speaking forums, whose members were much more diverse, often including those who were hostile to Islam or at least non-religious, and who were more likely to indulge in polemic towards other forum participants $(2009,122)$.

\section{Contagion}

Homophily can only be a partial explanation of how echo chambers develop (and which does not implicate the Internet). In a contagion model of influence, network properties facilitate or restrict the passage of particular views throughout the network. An echo chamber must surely include some kind of contagion mechanism; otherwise 
it is not clear how ideas circulate and become radical, or how moderate views are replaced with the extremist in-group consensus.

How might such contagion work? The echo chamber thesis implies that the group gradually reaches a consensus more extreme than the starting positions of (many of) the participants. This suggests more interaction leads to similarities of attitudes. However, in most contagion theories, this principle is counterbalanced by a principle of reflected exclusivity - "the degree of influence person $j$ has on person $i$ 's evaluation ... is inversely proportional to the amount of time $j$ spends with all others" (Krackhardt \& Brass 1994, 219). Reflected exclusivity should dampen the homogenisation of attitudes across a network - and so in an echo chamber one would expect conversely that reflected exclusivity plays a relatively small role precisely because an echo chamber does homogenise attitudes.

It follows that members' influence on each other should be high, and therefore that their external networks are relatively insignificant, meaning that the members are unlikely to conform to the networked individual's profile. However, it is unclear how the Internet could be the cause of such alienation. If it was, then the implication is that a networked individual would have to enter the echo chamber and somehow lose his or her diverse connections, replacing them with more and stronger connections within the echo chamber. Few mechanisms have been proposed for this to happen; one popular idea is that people are adopted into cults, brainwashed and alienated from their contacts, but as we argue elsewhere (Stevens \& O'Hara 2014), this is not a common scenario and is often misleadingly reported.

Furthermore, individuals in the echo chamber must be more open to influence than others. Granovetter (1978) suggested that people would have a threshold below which they would not be influenced by others; if, within some network, they were influenced by a sufficiently large number in sufficiently many sufficiently strong communications, then the threshold would be breached and they would become likely to adopt the views they had been introduced to. In an echo chamber, if views are to spread effectively, there must be sufficient people with low thresholds to allow a view to take hold. Once enough people in the group have 'caught' the view, developing a nascent monadic cluster, then it will spread among others.

Is such a model realistic? Even if there was a group of easily-influenced people, the spread of a view would require not only that these people could go on to influence others, but that they would be sufficient in number to 'crowd out' alternative views. Yet in most cases the supposedly less-susceptible people with higher thresholds will be receiving information from not only the developing monadic cluster (cf. Gergen 2008), but from all the people they have weaker connections with.

These others with whom our religious members have weaker ties turn out to be rather important. For example, a study of Facebook showed that even though people are more likely to share and discuss content with close friends, they still receive more information and more new information from distant sources (Bakshy et al 2012). On Facebook at least, most information flow happens as a result of relatively weak links across the network. Hence it is something of a leap to say that we can expect to see many situations where a cluster of people in a church or political group influences the rest to the exclusion of outsiders. Even if the conditions for a small monadic cluster obtain, then as the cluster begins to grow weaker ties will become more influential. 
As Monge and Contractor argue, contagion models are less plausible then they might initially seem, discounting rare and exceptional circumstances. "Missing in the contagion model is the typical ebb and flow of messages through networks that typifies human communication. In human interaction messages containing different ideas, values, and attitudes flow back and forth among people as they negotiate resolutions. The most typical outcome is modifications to the different positions each person held at the outset of the contagion process, modifications that influence both contaminators and the contaminated" (Monge \& Contractor 2003, 184-185).

\section{Conclusion}

A critical review of theory and empirical work helps to undermine the echo chamber theory of the Internet. Some commentators defend the value of echo chambers, at least in certain circumstances (Weinberger 2004). Research by Wellman and others has suggested that people are members of many networks, and that new technology does not seem to be creating hordes of alienated people as useful fodder for extremist echo chambers. Most people have many connections which would tend to reduce the influence of particular sets of ideas, while conversely (Gruzd \& Roy 2014) found that engaging with the enemy does not necessarily make a group less partisan. And when we look at the mechanisms for spreading ideas through a network, we see that echo chambers will perhaps be more likely to develop where there are coherent clusters, and when ideas spread through homophily and contagion. But homophily seems to be more powerful offline, requiring demographic contingencies in addition to the technology, while contagion seems to require an unusual degree of homogeneity, alienation and openness to influence from group members. It is possible that Internet technology could exacerbate problems with communities of such people, but can hardly be held responsible for their existence.

This should not surprise us. Research into the facilitation of social networks by technology has thrown up paradoxes and ambivalent conclusions rather than direct unequivocal effects. The introduction of email and other electronic methods of communication in organizations, for example, produced both centralization and decentralization (Fisher 1992, Rice 1994, O’Mahony \& Barley 1999, Monge \& Contractor 2003, 231-233), an example of what Tehranian (1990) has called the dual effects hypothesis. This may help answer our question of how echo chambers can both support authenticity (Mutz 2002, Weinberger 2004) and diminishing it (Sunstein 2007, Lanier 2011): they can do both.

\section{Acknowledgements}

The work of KMO is supported under SOCIAM: The Theory and Practice of Social Machines. The SOCIAM Project is funded by the UK Engineering and Physical Sciences Research Council (EPSRC) under grant number EP/J017728/1 and comprises the Universities of Southampton, Oxford and Edinburgh. The authors are grateful to comments made by anonymous referees to earlier versions of this paper.

\section{References}

Lada A. Adamic \& Natalie Glance, 'The political blogosphere and the 2004 U.S. election: divided they blog', $2^{\text {nd }}$ Annual Workshop on the Weblogging Ecosystem: Aggregation, Analysis and Dynamics, WWW05, 2005. 
Jisun An, Meeyoung Cha, Krishna P. Gummadi, Jon Crowcroft \& Daniele Quercia, 'Visualising media bias through Twitter', $6^{\text {th }}$ International AAAI Conference on Weblogs and Social Media, 2012.

Jisun An, Daniele Quercia \& Jon Crowcroft, 'Fragmented social media: a look at selective exposure to political news', World Wide Web Conference 2013 Companion, 2013, http://www2013.org/companion/p51.pdf.

Sinan Aral \& Marshall Van Alstyne, 'The diversity-bandwidth tradeoff', American Journal of Sociology, 117(1) (2011), 90-171.

Etyan Bakshy, Itamar Rosenn, Cameron Marlow \& Lada Adamic, 'The role of social networks in information diffusion', Proceedings of the World Wide Web Conference 2012, Lyon, 2012.

Eileen Barker, 'Crossing the boundary: new challenges to religious authority and control as a consequence of access to the Internet', in Morten T. Højsgaard \& Margit Warburg (eds.), Religion and Cyberspace, Abingdon: Routledge, 2005, 67-85.

Eli Berman \& David D. Laitin, 'Religion, terrorism and public goods: testing the club model', Journal of Public Economics, 92 (2008), 1942-1967.

Gary Bunt, iMuslims: Rewiring the House of Islam, London: Hurst, 2009.

Scott W. Campbell \& Nojin Kwak, 'Political involvement in "mobilized" society: the interactive relationships among mobile communication, network characteristics, and political participation', Journal of Communication, 61 (2011), 1005-1024.

Douglas Carswell, The End of Politics: And the Birth of iDemocracy, London: Biteback, 2012.

Manuel Castells, The Information Age: Economy, Society and Culture Volume 1: The Rise of the Network Society, $2^{\text {nd }}$ edition, Malden, MA: Blackwell, 2000.

Mohammed el-Nawawy \& Sahar Khamis, Islam Dot Com: Contemporary Islamic Discourses in Cyberspace, New York: Palgrave Macmillan, 2009.

Claude S. Fischer, America Calling: A Social History of the Telephone to 1940, Berkeley: University of California Press, 1992.

Claude S. Fischer, 'Bowling Alone: what's the score?' Social Networks, 27(2) (2005), 155-167.

Joseph Galaskiewicz, Exchange Networks and Community Politics, Newbury Park, CA: Sage, 1979.

Kenneth J. Gergen, 'Mobile communication and the transformation of the democratic process', in James E. Katz (ed.), Handbook of Mobile Communication Studies, Cambridge MA: M.I.T. Press, 2008, 297-310.

Anthony Giddens, A Contemporary Critique of Historical Materialism Volume 1: Power, Property and the State, London: Macmillan, 1980.

Mark Granovetter, 'Threshold models of diffusion and collective behavior', Journal of Mathematical Sociology, 9 (1978), 165-179.

Anatoliy Gruzd \& Jeffrey Roy, 'Investigating political polarization on Twitter: a Canadian perspective', Policy and Internet, 6(1) (2014), 28-45. 
Jürgen Habermas, The Structural Transformation of the Public Sphere, Thomas Burger \& Frederick Lawrence (trans.), Cambridge: Polity Press, 1989.

Jürgen Habermas, Between Naturalism and Religion, Ciaran Cronin (trans.), Cambridge: Polity Press, 2008.

Eszter Hargittai, Jason Gallo \& Matthew Kane, 'Cross-ideological discussions among conservative and liberal bloggers', Public Choice, 134 (2008), 67-86.

Sam Harris, The End of Faith: Religion, Terror and the Future of Reason, London: Free Press, 2005.

Matthew Hindman, The Myth of Digital Democracy, Princeton: Princeton University Press, 2009.

Massimo Introvigne, 'A symbolic universe: information terrorism and new religions in cyberspace', in Morten T. Højsgaard \& Margit Warburg (eds.), Religion and Cyberspace, Abingdon: Routledge, 2005, 102-117.

Jonathan Kay, Among the Truthers: A Journey Through America's Growing Conspiracist Underground, New York, HarperCollins, 2011.

Norbert L. Kerr, 'Efficacy as a causal and moderating variable in social dilemmas', in Wim Liebrand, David Messick \& Henk Wilke (eds.), Social Dilemmas: Theoretical Issues and Research Findings, Oxford: Pergamon Press, 1992, 59-80.

Sarah Kliff, Rep. Todd Akin is Wrong About Rape and Pregnancy But He's Not Alone, http://www.washingtonpost.com/blogs/wonkblog/wp/2012/08/20/rep-todd-akin-iswrong-about-rape-and-pregnancy-but-hes-not-alone/, $20^{\text {th }}$ Aug, 2012.

David Krackhardt \& Daniel J. Brass, 'Intraorganizational networks: the micro side', in Stanley Wasserman \& Joseph Galaskiewicz (eds.), Advances in Social Network Analysis: Research in the Social and Behavioral Sciences, Thousand Oaks, CA: Sage, 1994, 207-229.

Nojin Kwak, Ann Williams, Xiaoru Wang \& Hoon Lee, 'Talking politics and engaging politics: an examination of the interactive relationships between structural features of political talk and discussion engagement', Communication Research, 32(1) (2005), 87-111.

Jaron Lanier, You Are Not a Gadget: a Manifesto, London: Penguin, 2011.

Charles Leadbeater, We-Think: Mass Innovation, Not Mass Production, London: Profile Books, 2008.

Yu-Ru Lin, James P. Bagrow \& David Lazer, 'More voices than ever? Quantifying media bias in networks', ArXiv.org, 2011, http://arxiv.org/pdf/1111.1227.pdf.

Renzo Lucioni, Voting Relationships Between Senators, http://renzolucioni.com/articles/senate-voting-relationships/, 17 $7^{\text {th }}$ Nov, 2013.

Peter Mandaville, Transnational Muslim Politics: Reimagining the Umma, Abingdon: Routledge, 2001.

Peter Mandaville, 'Reimagining the Ummah? Information technology and the changing boundaries of political Islam', in Ali Mohammadi (ed.), Islam Encountering Globalization, London: Routledge Curzon, 2002, 61-90.

Alan Martin, 'The Web's “echo chamber" leaves us none the wiser', Wired, $1^{\text {st }}$ May, 2013, http://www.wired.co.uk/news/archive/2013-05/1/online-stubbornness. 
Gerald Marwell \& Pamela Oliver, The Critical Mass in Collective Action: A MicroSocial Theory, Cambridge: Cambridge University Press, 1993.

Robert D. McPhee \& Steven R. Corman, 'An activity-based theory of communication networks in organizations, applied to the case of a local church', Communications Monographs, 62 (1995), 132-151.

Peter R. Monge \& Noshir S. Contractor, Theories of Communication Networks, New York: Oxford University Press, 2003.

Karen Mossberger, Caroline J. Tolbert \& Ramona S. McNeal, Digital Citizenship: The Internet, Society and Participation, Cambridge, MA: MIT Press, 2008.

Diana C. Mutz, 'The consequences of cross-cutting networks for political participation', American Journal of Political Science, 46(4) (2002), 838-855.

Diana C. Mutz \& Paul S. Martin, 'Facilitating communication across lines of political difference: the role of mass media', American Political Science Review, 95(1) (2001), 97-114.

Kieron O'Hara, Noshir S. Contractor, Wendy Hall, James A. Hendler \& Nigel Shadbolt, 'Web Science: understanding the emergence of macro-level features on the World Wide Web', Foundations and Trends in Web Science, 4(2/3) (2013), 103-267.

Kieron O'Hara \& David Stevens, 'The Devil's long tail: religious moderation and extremism on the Web', IEEE Intelligent Systems, 24(6) (2009), 37-43.

Siobhan O'Mahony \& Stephen R. Barley, 'Do digital telecommunications affect work and organization? The state of our knowledge', in Robert I. Sutton \& Barry M. Staw (eds.), Research in Organizational Behavior Vol.21, Stamford CT: JAI Press, 1999, 125-162.

Eli Pariser, The Filter Bubble: What the Internet is Hiding From You, London: Viking, 2011.

David Piff \& Margit Warburg, 'Seeking for truth: plausibility assignment on a Baha'i email list', in Morten T. Højsgaard \& Margit Warburg (eds.), Religion and Cyberspace, Abingdon: Routledge, 2005, 86-101.

Robert D. Putnam \& David E. Campbell, American Grace: How Religion Divides and Unites Us, New York: Simon \& Schuster, 2010.

Lee Raimie \& Barry Wellman, Networked: the New Social Operating System, Cambridge, MA: MIT Press, 2012.

Ronald E. Rice, 'Network analysis and computer-mediated communications systems', in Stanley Wasserman \& Joseph Galaskiewicz (eds.), Advances in Social Network Analysis: Research in the Social and Behavioral Sciences, Thousand Oaks, CA: Sage, 1994, 167-206.

Olivier Roy, Globalized Islam: The Search for a New Ummah, New York: Columbia University Press, 2004.

John R. Schermerhorn Jr, 'Information sharing as an interorganizational activity', Academy of Management Journal, 20 (1977), 148-153.

Roger Scruton, The West and the Rest: Globalization and the Terrorist Threat, London: Continuum, 2002. 
Stuart Sim, Fundamentalist World: The New Dark Age of Dogma, Duxford: Icon, 2004.

Aaron Smith, The Internet and Campaign 2010, The Pew Internet and American Life Project, $17^{\text {th }}$ Mar, 2011.

David Stevens \& Kieron O'Hara, The Devil's Long Tail: Religious and Other Radicals in the Internet Marketplace, London: Hurst Publishers, 2014.

Cass R. Sunstein, Infotopia: How many minds produce knowledge, Oxford: Oxford University Press, 2006.

Cass R. Sunstein, Republic.com 2.0, Princeton: Princeton University Press, 2007.

Cass R. Sunstein, 'Neither Hayek nor Habermas', Public Choice, 134 (2008), 87-95.

James Surowiecki, The Wisdom of Crowds: Why the Many Are Smarter Than the Few, London: Little, Brown, 2004.

Nassim Nicholas Taleb, The Black Swan, London: Allen Lane, 2007.

Don Tapscott \& Anthony D. Williams, Wikinomics: How Mass Collaboration Changes Everything, London: Atlantic Books, 2007.

Don Tapscott \& Anthony D. Williams, Macrowikinomics: Rebooting Business and the World, London: Atlantic Books, 2010.

Majid Tehranian, Technologies of Power: Information Machines and Democratic Prospects, Norwood, NJ: Ablex, 1990.

Hua Wang \& Barry Wellman, 'Social connectivity in America: changes in adult friendship network size from 2002 to 2007', American Behavioral Scientist, 53(8) (2010), 1148-1169.

David Weinberger, 'Is there an echo in here?' Salon, 20 ${ }^{\text {th }}$ Feb, 2004, http://www.salon.com/technology/feature/2004/02/20/echo_chamber/.

Barry Wellman, 'Is Dunbar's number up?' British Journal of Psychology, 103 (2012), 174-176.

Barry Wellman, Amanda Garofalo \& Vanessa Garofalo, 'The Internet, technology and connectedness', Transition, Winter 2009, 5-7.

Barry Wellman \& Caroline Haythornthwaite (eds.), The Internet in Everyday Life, Malden, MA: Blackwell, 2002. 